\title{
The Impact of University Efficiency and Financial Development on Technology Transfer from the Perspective of Economic Innovation
}

\author{
Jinlin Liu ${ }^{1}$, Jiaqing Liu ${ }^{2, *}$ \\ ${ }^{1}$ Department of Management Science and Engineering Management, Guizhou University of Finance and Economics, Guiyang, China \\ ${ }^{2}$ Department of Business Administration, Guizhou University of Finance and Economics, Guiyang, China
}

\begin{abstract}
Based on the provincial panel data of 30 provinces in China from 2009 to 2018, this paper uses the system GMM estimation method to examine the impact of university efficiency and financial development on technology transfer from the perspective of economic innovation, and validates the hypotheses of theoretical analysis. The research results show that university efficiency may promote technology agglomeration, but significantly inhibit technology transfer, which is not conducive to directly promoting economic innovation; while financial development significantly promotes technology transfer, which is conducive to promoting economic innovation. Finally, based on the above conclusions, in order to better promote economic innovation and technology transfer, and promote the sustainable development of the national innovation system, this article puts forward corresponding policy recommendations.
\end{abstract}

\section{Introduction}

After decades of rapid growth, China's economy has now entered a new normal. Economic innovation and technology transfer have become important ways to enhance the overall innovation capacity and competitiveness of the country. In the aspect of technological innovation, universities are important places of scientific research. As an important part of national economic innovation system, university efficiency fully reflects the ability of transformation of scientific and technological achievements and is an important link to promote economic growth. At the same time, the development of national economy is inseparable from the external environment of financial development. In addition, technology transfer has become an important means of implementing innovation-driven development, which is conducive to promoting the steady development of the regional economy. Thus, university efficiency and financial development, as key components of economic innovation, together with technology transfer, are committed to the sustainable development of the national innovation system. But what is the relationship between them? Can the improvement of university efficiency promote technology transfer? How does financial development affect technology transfer? In view of this, in the face of the growing gap in economic development between regions, this article examines the impact of university efficiency and financial development on technology transfer from the perspective of economic innovation, and then puts forward some recommendations to better promote economic innovation and technology transfer, this is of great significance to the sustainable development of the national innovation system.

There are many researches on the influencing factors of technology transfer, but on the impact of financial development on technology transfer, scholars mainly examine the relationship between financial development and technology transfer from different perspectives of financial development. For example, Gross believes that developing a venture capital system and optimizing IPOs are important measures for the rapid development of the technology transfer industry ${ }^{[1]}$; research by Audretsch et al. shows that technology transfer is closely related to entrepreneurial finance ${ }^{[2]}$. In addition, few documents directly study the impact of university efficiency on technology transfer, but some of them have laid a foundation for exploring the relationship between the two For example: Miller et al. conducted a systematic literature review on university technology transfer ${ }^{[3]}$; Colombelli et al. analyzed the internal mechanism of university technology transfer in detail ${ }^{[4]}$.

In summary, few scholars have examined the impact of university efficiency on technology transfer. Secondly, the existing documents basically use static panel models or OLS estimation methods for empirical research, and technology transfer is a cumulative process, the earlier technology transfer will have an impact on the later technology transfer. At the same time, the endogenous problem in the model will influence the research conclusion, so the use of these two estimation methods is biased. Based on this, this article will expand from the following two aspects: firstly, from the perspective of

\footnotetext{
* Corresponding author: jiaqingliu@yeah.net
} 
economic innovation, we will examine the impact of university efficiency and financial development on technology transfer in order to better promote economic innovation and technology transfer; the second is to choose the dynamic panel data model of the system GMM method for empirical research in order to pursue more accurate results. The structure of this article is as follows: The first part is the introduction; the second part is the research hypotheses and method; the third part is the results and discussion; the fourth part is the conclusion.

\section{Research hypotheses and method}

\subsection{University efficiency and technology transfer}

Universities are important places for cultivating innovative talents and promoting the transformation of achievements. They are of great significance for promoting technology transfer and accelerating high-quality economic development. The value brought by the transformation of university scientific and technological achievements is the most important direct source of China's economic growth. Therefore, many scholars have studied the technology transfer activities of universities. For example, Kirby et al. examined the means by Egyptian universities to promote technology transfer and promote entrepreneurial innovation ${ }^{[5]}$. In addition, Tian and Guo proposed that the efficiency of the transformation of scientific and technological achievements in Xi'an universities is low, mainly reflected in the fact that the teachers and funds of universities are directly used to serve social development rather than direct technology transfer. Besides, the technological innovation ability of universities is low, has not been an effective driver of growth ${ }^{[6]}$. Therefore, this article proposes hypothesis 1 :

Hypothesis 1: The improvement of university efficiency may promote technology agglomeration, but it will hinder technology transfer, which is not conducive to promoting economic innovation.

\subsection{Financial development and technology transfer}

A mature financial development environment can effectively gather and allocate funds, and improve the efficiency of capital utilization in order to provide funding requirements for innovation, which will inevitably directly promote technological progress and economic growth to a large extent. In the study of financial development and technological innovation on economic growth, Paroussos et al. investigated the role of financial function and technological innovation in the growth of Italian green economy, and found that the development of finance can promote technological innovation, and then achieve economic growth ${ }^{[7]}$. In addition, some scholars have found that technological innovation and technology transfer activities are conducive to enhancing regional sustainable development capabilities, and there is also a very close relationship between the two ${ }^{[8]}$. Therefore, this article proposes hypothesis 2 :

Hypothesis 2: Financial development has a significant positive impact on technology transfer, which is conducive to promoting economic innovation.

\subsection{Model setting and variable selection}

Based on the above analysis, this paper considers the dynamic panel model which is influenced by the lag of one phase of technology transfer. The model settings and variable selection are as follows:

$$
\begin{aligned}
& \ln T T_{i t}=\alpha+\beta_{0} \ln T T_{i t-1}+\beta_{1} U E_{i t}+\beta_{2} F D_{i t}+\beta_{3} \ln G D P_{i t} \\
& +\beta_{4} \text { Open }_{i t}+\beta_{5} \text { Human }_{i t}+\beta_{6} \text { GIST }_{\text {it }}+\text { Province } \\
& + \text { Year }_{i}+\varepsilon_{i t}
\end{aligned}
$$

(1) The explained variable. Technology transfer (lnTT) is measured by the transaction amount of technology contracts.

(2) Explanatory variables. University efficiency (UE), firstly select university R\&D personnel and university $\mathrm{R} \& \mathrm{D}$ expenditure as the input level indicators, and select the number of technology transfer contracts signed and the actual income of technology transfer as the output level indicators; then use the DEA-Malmquist index method to calculate the university efficiency . Financial development (FD) is measured by the ratio of the total loan balance to the deposit balance of financial institutions at the end of the year.

(3)Control variables. The selected control variables are related variables that affect economic innovation and technology transfer at the same time. The level of economic development ( $\operatorname{lnGDP}$ ) is measured by the regional GDP; the degree of openness (Open) is measured by the proportion of the total import and export value in the regional GDP; the level of human capital (Human) is measured by the proportion of the population with a college degree or above in the population over the age of 6; government's investment in science and technology (GIST) is measured by the proportion of government funds in the internal R\&D expenditure.

In terms of method selection, under the premise that the instrumental variables are effective, in order to overcome the endogenity and heteroscedasticity of the model, and to pursue the accuracy of the research results, this paper adopts the two-step system GMM estimation method, statistical analysis of the data and empirical estimation of the model use DEAP2.1 and Stata14.0 statistical software to complete.

\section{Results and discussion}

\subsection{Descriptive statistical results}

This article uses 300 panel data from 30 provinces in China from 2009 to 2018 as samples. The descriptive statistics of related statistics and variables are shown in Table 1. 
Table 1. Descriptive statistical results

\begin{tabular}{|c|c|c|c|c|c|}
\hline Variable & Obs & Mean & S.D. & Min & Max \\
\hline $\operatorname{lnTT}$ & 300 & 4.3663 & 1.7804 & -0.5978 & 8.5087 \\
\hline UE & 300 & 0.5439 & 0.2866 & 0.1360 & 1.0000 \\
\hline FD & 300 & 0.7522 & 0.1422 & 0.3995 & 1.2988 \\
\hline $\operatorname{lnGDP}$ & 300 & 9.6583 & 0.8900 & 6.9859 & 12.0559 \\
\hline Open & 300 & 0.2791 & 0.3246 & 0.0144 & 1.5485 \\
\hline Human & 300 & 0.1216 & 0.0731 & 0.0233 & 1.5485 \\
\hline GIST & 300 & 0.2445 & 0.1370 & 0.0687 & 0.6081 \\
\hline
\end{tabular}

\subsection{Regression analysis results and discussion}

Table 2 shows the results of regression analysis. According to the estimated results of OLS and fixed-effects models, the influence of explanatory variables on the explained variables has different results under these two methods. This is mainly due to the dynamic panel data contained in the model. These two models are difficult to solve the problem of endogeneity. Therefore, this paper introduces the system GMM estimation method to re-estimate the dynamic panel data model. Among them, the AR(1) test and AR(2) test in the model show that there is indeed a first-order serial correlation and a second-order serial uncorrelation in the residual term of the estimation equation; and the result of Sargan's over-identification test did not reject the null hypothesis of the validity of the instrumental variables. This shows that the dynamic panel model of first-order autoregressive is reasonable, and the setting of instrumental variables is also effective.

Table 2. Regression analysis results

\begin{tabular}{|c|c|c|c|}
\hline variable & OLS & $\begin{array}{c}\text { Fixed } \\
\text { effects }\end{array}$ & $\begin{array}{c}\text { System } \\
\text { GMM }\end{array}$ \\
\hline $\ln T T_{\text {it- } 1}$ & $0.909 * * *$ & $0.590^{* * *}$ & $0.610^{* * *}$ \\
\hline UE & -0.602 & 0.066 & $-0.427^{* *}$ \\
\hline FD & 0.149 & 0.621 & $1.861^{* * *}$ \\
\hline $\operatorname{lnGDP}$ & $0.163^{* * *}$ & $0.547^{* * *}$ & $1.002^{* * *}$ \\
\hline Open & 0.333 & 0.050 & $0.710^{* * *}$ \\
\hline Human & -0.202 & 0.660 & $-0.305^{*}$ \\
\hline GIST & $0.694 * *$ & $1.836^{* *}$ & $3.357^{* * *}$ \\
\hline C & -1.255 & $-4.394 * * *$ & $-10.009^{* * *}$ \\
\hline $\mathrm{R}^{2}$ & 0.942 & 0.924 & \\
\hline Obs & 300 & 300 & 300 \\
\hline AR (1) & & & 0.035 \\
\hline AR (2) & & & 0.202 \\
\hline Sargan & & & 0.535 \\
\hline Note: & & & \\
\hline
\end{tabular}

Note: $* * *, * *$, and $*$ indicate significant at the levels of $1 \%, 5 \%$, and $10 \%$, respectively.
According to the regression result of the system GMM, the first-order lag term of technology transfer has passed the significance test, and the coefficient is positive, indicating that the improvement of technology transfer level has a cyclic accumulation effect, and it is true that the earlier technology transfer will have a positive impact on the later technology transfer. Therefore, we need to pay attention to the role of technology transfer in promoting technological innovation and economic growth.

As far as the explanatory variables are concerned, university efficiency is a significant obstacle to technology transfer. The possible reason is that universities directly serve social development by aggregating and integrating all aspects of development needs and resources, which promotes technology agglomeration rather than direct technology transfer. At the same time, many universities in China have relatively low efficiency in the conversion of scientific and technological achievements for a long time. Besides, the independent innovation capability of university needs to be improved, and the outputs cannot fully match the needs of the enterprise, thus hindering the transfer of technology, which makes it difficult to create new economic value and promote economic innovation. This conclusion is consistent with hypothesis 1 . In addition, financial development has significantly promoted technology transfer. The likely reason is that financial development has made the financial services system more robust. At the same time, financial development has also provided guarantees for technology transfer, and met the financial needs at different stages of technology transfer. Besides, financial development also accelerated the speed and efficiency of the transformation of scientific and technological achievements, which is also conducive to increasing the added value of new products and thus promoting economic innovation. This conclusion is consistent with hypothesis 2 .

The regression results in Table 2 also reveal some other valuable information for us. Among the control variables, the coefficients of the level of economic development, the degree of openness and the government's investment in science and technology are all significantly positive, indicating that these factors have important positive significance in promoting technology transfer, and can also effectively promote economic and technological innovation. However, the level of human capital is significantly negative. The reason is that if the level of human capital increases, it means that more highly educated human resources will gather. However, this kind of human agglomeration does not directly promote technology transfer. In addition, the enthusiasm of scientific researchers in promoting the transformation of scientific and technological achievements is not high, and human capital does not fully play its role in promoting technology transfer and economic growth. This also explains to a certain extent why the level of technology transfer will decline as the efficiency of universities increases. 


\section{Conclusion}

University efficiency and financial development are the key links of national economic innovation system, and they can play important roles in promoting technology transfer and economic growth. Therefore, based on the provincial panel data of 30 provinces in China from 2009 to 2018, this paper uses the system GMM estimation method to analyze the relationship between university efficiency, financial development and technology transfer at the national level, and validates the hypotheses of the theoretical analysis. The research results show that university efficiency may promote technology agglomeration, but significantly inhibit technology transfer, which is not conducive to directly promoting economic innovation; while financial development significantly promotes technology transfer, which is conducive to promoting economic innovation. Finally, based on the above conclusions, in order to better promote economic innovation and technology transfer, and promote the sustainable development of the national innovation system, this article puts forward corresponding policy recommendations on universities and finance from the perspective of economic innovation.

In the future, we should combine the current situation and problems of the transformation of scientific and technological achievements in China to strengthen the effective combination of technological innovation and economic development. In addition, we should inject strong impetus into economic and social development through technological innovation, and we should also promote economic development through the transformation of scientific and technological achievements. Specifically, universities should set up a docking platform between technology providers and technology demanders, and promote the transformation of scientific and technological achievements by relying on professional technology transfer offices in order to improve the success rate of technology transfer. At the same time, the university should strengthen the independent innovation ability and the enthusiasm of the scientific research personnel to promote the technology transfer through relying on the human capital in order to realize the technology innovation and the high-quality development of the economy. Secondly, the government should strengthen financial support, and further strengthen the role of financial guidance. At the same time, the government should also maintain the long-term stability of the loan-to-deposit ratio and provide a healthy and orderly external financial environment for economic development to ensure the fund demand at different stages of technology transfer. And on this basis, the national economy can maintain long-term stable development, economic innovation can be achieved effectively in a short time.

\section{Acknowledgments}

This article is one of the phased achievements of the Natural Science Foundation of China's "Study on the
Regional Dynamic Evolutionary Mechanisms of Intelligent Technology, Factor Substitution and Industrial Synergistic Agglomeration" (fund No: 72064003).

\section{References}

1. Gross,C.M. (2013)The Growth of China's Technology Transfer Industry over the Next Decade: Implications for Global Markets. The Journal of Technology Transfer, 38: 716 -747.

2. Audretsch,D.B., Lehmann,E.E., Paleari,S. (2016) Entrepreneurial Finance and Technology Transfer. The Journal of Technology Transfer, 41: 1-9.

3. Miller,K., Mcadam,R., Mcadam.M. (2018)A systematic literature review of university technology transfer from a quadruple helix perspective: Toward a research agenda. R\&D Management, 1: 7-24.

4. Colombelli,A., Marco,A.D., Paolucci,E. (2020) University technology transfer and the evolution of regional specialization: The case of Turin. The Journal of Technology Transfer, 9: 158-164.

5. Kirby,D.A, Hadidi,H.H.E, Link,A.N. (2019) University technology transfer efficiency in a factor driven economy: The need for a coherent policy in Egypt. The Journal of Technology Transfer, 44: 1367-1395.

6. Tian,G.H., Guo,Y.Y. (2019)The status quo, problems and countermeasures of technology transfer in colleges and universities in Xi'an. Chinese University Science \& Technology, 8: 93-96.

7. Paroussos,L., Fragkiadakis,K., Fragkos,P. (2020) Macro-economic analysis of green growth policies: the role of finance and technical progress in Italian green growth. Climatic Change, 160: 591-608.

8. Nie,Q. (2015) Analysis on the Dynamic Impact of Technological Innovation and Technology Transfer on Regional Sustainable Development: Taking Beijing as an Example. Science and Technology Management Research, 35: 71-76. 